\title{
Diagnostic yield of capsule endoscopy in the setting of iron deficiency anemia without evidence of gastrointestinal bleeding
}

\author{
Jessica Tong, Sigrid Svarta MD, George Ou MD, Ricky Kwok BSc, Joanna Law MD, Robert Enns MD
}

\begin{abstract}
J Tong, S Svarta, G Ou, R Kwok, J Law, R Enns. Diagnostic yield of capsule endoscopy in the setting of iron deficiency anemia without evidence of gastrointestinal bleeding. Can J Gastroenterol 2012;26(10):687-690.
\end{abstract}

BACKGROUND: The diagnostic yield of capsule endoscopy (CE) in the setting of iron deficiency anemia (IDA) without evidence of occult/overt bleeding has been questioned. Often, these patients have nongastrointestinal causes of iron deficiency but undergo CE to exclude a potential small bowel source.

OBJECTIVE: To assess the diagnostic yield of CE, the characteristics predicting positive results, the presumed etiology of IDA in negative/ normal CE and patient management after CE.

METHODS: A retrospective review of 934 patients who underwent CE between December 2001 and February 2010 was conducted. All patients had undergone previous negative endoscopic examinations before CE. Patients with IDA but no evidence of overt/occult bleeding were separated into three categories based on CE findings: group A - positive; group B - negative/normal; and group $\mathrm{C}$ - incomplete/indeterminate. RESULTS: A total of 101 capsules in 97 patients were evaluated. Group A had 25 subjects with positive findings on CE, 18 of whom were managed supportively. Group B consisted of 69 subjects with negative/normal CE, 60 of whom were treated supportively. Group C consisted of three subjects with incomplete CE results.

CONCLUSION: In patients with IDA without evidence of gastrointestinal bleeding, CE had a low diagnostic yield (25.7\%), which increased to $45.5 \%$ after adjusting for low dietary iron intake and menorrhagia. However, CE did not alter management in most patients regardless of findings, and many of the lesions requiring intervention were within reach of standard endoscopes. No predictor of positive results was found. In this patient population, careful history taking and thorough endoscopy could improve CE utilization, although its value is still relatively limited.

Key Words: Capsule endoscopy; Iron deficiency anemia

\author{
Le rendement diagnostique de l'endoscopie \\ capsulaire en cas d'anémie ferriprive sans trace de \\ saignement gastro-intestinal
}

HISTORIQUE : Le rendement diagnostique de l'endoscopie capsulaire
(EC) en cas d'anémie ferriprive (AFP) sans trace de saignements occultes
ou apparents est remis en question. Souvent, ces patients présentent une
cause non gastro-intestinale d'AFP, mais subissent une EC pour exclure la
possibilité que l'intestin grêle en soit responsable. OBJECTIF : Évaluer le rendement diagnostique de l'EC, les caractéristiques évocatrices de résultats positifs, l'étiologie présumée de l'AFP en cas d'EC négative ou normale et la prise en charge des patients après l'EC.

MÉTHODOLOGIE : Les chercheurs ont effectué une analyse rétrospective de 934 patients qui ont subi une EC entre décembre 2001 et février 2010. Tous les patients avaient subi des examens endoscopiques négatifs avant l'EC. Les chercheurs ont réparti en trois catégories les patients atteints d'AFP ne présentant pas de trace de saignements apparents ou occultes selon les résultats de l'EC : groupe A - positif, groupe B - négatif ou normal, et groupe $\mathrm{C}$ - incomplet ou indéterminé.

RÉSULTATS : Au total, les chercheurs ont évalué 101 capsules chez 97 patients. Dans le groupe A, 25 sujets ont obtenu des résultats positifs d'EC, dont 18 ont reçu une prise en charge de soutien. Le groupe B se composait de 69 sujets dont l'EC était négative ou normale, et dont 60 ont reçu un traitement de soutien. Le groupe $\mathrm{C}$ était formé de trois sujets dont les résultats de l'EC étaient incomplets.

CONCLUSION : Chez les patients atteints d'AFP sans trace de saignement gastro-intestinal, l'EC avait un faible rendement diagnostique $(25,7 \%)$, qui est passé à 45,5\% après rajustement nécessaire à cause du faible apport de fer diététique et de la ménorragie. Cependant, l'EC ne modifiait pas la prise en charge chez la plupart des patients, quels que soient les résultats, et bon nombre des lésions exigeant une intervention pouvaient être traitées à l'aide d'un endoscope standard. Les chercheurs n'ont découvert aucun prédicteur de résultats positifs. Dans cette population de patients, une anamnèse attentive et une endoscopie approfondie pourraient améliorer l'utilisation de l'EC, même si sa valeur demeure relativement limitée.
Capsule endoscopy (CE), a modality used to visualize the entire small bowel (SB) mucosa in a noninvasive manner, has been used in clinical practice for 10 years (1). As the indications for this modality have expanded and, as more studies confirm its efficacy, the demand for the procedure has increased.

The most common use of CE has been for the evaluation of obscure gastrointestinal bleeding, overt and/or occult, including patients with iron deficiency anemia (IDA), with no culprit lesions found on standard endoscopic examinations $(2,3)$. The diagnostic yield of $\mathrm{CE}$ in the setting of IDA without any evidence of occult or overt bleeding has, however, been questioned $(7,8)$. Often, these patients have other causes of iron deficiency than gastrointestinal (GI) bleeding, but undergo CE nevertheless to ensure there is no evidence of an occult source that might have been missed or is 'out of reach' with standard endoscopes. Because the benefit of CE may be different for varied indications, it becomes more important to identify specific patient subgroups in which CE has the greatest utility to ensure appropriate use of this resource (4-6).

The diagnostic yield of CE may be low in the setting of IDA without evidence of GI bleeding, and most patients in this group will not benefit from a small bowel capsule study. We also hypothesize that other disorders causing decreased intake or absorption of iron are more likely to be the cause of anemia (9); these include celiac disease, other mucosal disorders that result in malabsorption (eg, Whipple disease, AIDS, etc), as well as patients in whom surgical diversion/resection of the proximal small intestine has been performed (eg, Bilroth procedures, bariatric surgery, etc) $(10,11)$.

The purpose of the present study was to evaluate our use of CE in patients with IDA and no evidence of occult/overt bleeding by establishing the positive yield of CE in our patients, determining whether there were specific characteristics that enhanced the likelihood of positive results, determining the etiology of iron deficiency in patients

Department of Medicine, Division of Gastroenterology, St Paul's Hospital, Vancouver, British Columbia

Correspondence: Dr Robert Enns, Division of Gastroenterology, St Paul's Hospital, Pacific Gastroenterology Associates, 770-1190 Hornby Street,

Vancouver, British Columbia V62 2K5. Telephone 604-688-6332 ext 222, fax 604-689-2004, email rob.enns@ubc.ca

Received for publication August 10, 2011. Accepted January 10, 2012 
TABLE 1

Positive findings on capsule endoscopy and management

\begin{tabular}{lll}
\hline Finding/location & Management & $\mathbf{n}$ \\
\hline Ulcers $(\mathbf{n}=\mathbf{7})$ & & \\
Duodenal $(\mathrm{n}=5)$ & Iron supplementation & 3 \\
& Discontinuation of NSAID(s) & 1 \\
& Helicobacter pylori treatment & 1 \\
Jejunal & Iron supplementation for mild IDA & 1 \\
Terminal ileal & Iron supplementation for mild IDA & 1 \\
Erosion/inflammation $(\mathbf{n}=\mathbf{9})$ & & \\
Hiatus hernia Cameron erosion & Iron supplementation & 1 \\
Duodenal $(\mathrm{n}=2)$ & Treated for celiac disease & 1 \\
& Monitor hemoglobin levels & 1 \\
Jejunal & Iron supplementation & 2 \\
Ileal $(\mathrm{n}=4)$ & Iron supplementation & 3 \\
& Treated for Crohn disease & 1 \\
Vascular lesion $(\mathbf{n}=6)$ & &
\end{tabular}

$\begin{array}{lll}\begin{array}{l}\text { Nonbleeding angiodysplastic } \\ \text { lesions in gastric antrum }\end{array} & \text { Argon plasma coagulation } & 1 \\ \begin{array}{l}\text { Nonbleeding angiodysplastic } \\ \text { lesions throughout small bowel }\end{array} & \text { Iron supplementation for mild IDA } & 1 \\ \text { Duodenal }(n=3) & \text { Iron supplementation } & 2 \\ & \begin{array}{l}\text { Intermittent, infrequent blood } \\ \text { transfusions }\end{array} & 1 \\ \text { Jejunal } & \text { Failed repeated endoscopic therapy } & 1 \\ & \text { and eventual intraoperative } & \\ & \text { endoscopy and cautery } & \end{array}$

Nonbleeding polyp/mass $(\mathrm{n}=2)$

Ulcerated small bowel polyps

(Cowden syndrome)

Suspected jejunal polyp

Iron supplementation

1

Not identified on double-balloon $\quad 1$ enteroscopy. Iron supplementation

Whipworms $(n=1)$

Cecum

Treated with mebendazole

1

IDA Iron deficiency anemia; NSAID Nonsteroidal anti-inflammatory drug

with negative capsule studies, and determining the management strategies in patients with negative capsule studies (ie, how management changed).

\section{METHODS}

A retrospective chart review of 934 patients who underwent CE studies in a tertiary care endoscopy unit at St Paul's Hospital, Vancouver, British Columbia (December 2001 to February 2010) was conducted. All CE procedures included in the study were performed using the PillCam (Given Imaging, Israel). Patients were asked to stop any oral iron supplementation five days before the procedure and to undergo bowel preparation the day before, which included a clear liquid-only diet and $2 \mathrm{~L}$ polyethylene glycol-electrolyte solution taken orally.

Data regarding demographics, medical and surgical history, medication use and follow-up for each patient were collected. The inclusion criterion for subjects in the present study was IDA without evidence of GI bleeding (ie, negative fecal occult blood test [FOBT] and no documented overt bleeding episode). Although a negative FOBT cannot exclude intermittent occult GI bleeding, a falsely negative test may suggest bleeding status and clinically sets this group apart from those with positive FOBT, which suggests active/recent bleeding more definitively. All patients had undergone at least one complete esophagogastroduodenoscopy and one colonoscopy as part of initial work-up for obscure gastrointestinal bleeding.

Patients were divided into three categories based on the presence of CE findings: group A - positive (anywhere from the stomach to the colon); group B - negative; and group $\mathrm{C}$ - incomplete/indeterminate study.
Group A patients were further divided into five subgroups according to the types of findings: nonbleeding polyp or mass; ulceration; erosion/inflammation; vascular lesion; and other (whipworm in one patient). Group B patients were simply classified into one subgroup: normal. Group $\mathrm{C}$ patients underwent incomplete CE due to equipment failure, retention in the stomach or failure to reach the cecum with small bowel imaging $<1 \mathrm{~h}$.

Data collected for positive findings (group A) were examined for the existence of certain clinical factors or comorbidities. Also assessed were management practices as recommended by the gastroenterologist. Management options included: supportive therapy (oral or parental iron supplementation); discontinuation of nonsteroidal anti-inflammatory drugs (NSAIDs); blood transfusion as required or simply monitoring hemoglobin level; treatment for pathology (ie, Crohn disease, celiac disease, etc); laparoscopy/open surgery; and repeat CE for incomplete investigations. Because some of the subjects were already on supportive therapy to no avail, it was determined whether and how treatment strategies for IDA were changed in those with normal small bowel imaging on their CE.

\section{RESULTS}

A total of 101 CEs in 97 patients (61 men [62.9\%], mean [ \pm SD] age $59.2 \pm 16.1$ years [range 15 to 89 years]) were performed. Four patients underwent repeat CE, the indications for which included suspected missed lesion $(n=1)$ and incomplete small bowel visualization $(n=3)$. Patients with recurrent problems were followed-up until a more definitive management plan was instituted.

\section{Group A}

Findings: Group A consisted of 25 subjects with positive findings on CE (25 of 97 [25.7\%]) with one of the positive findings on repeat CE. The 25 positive findings included: ulceration $(n=7)$; erosion or inflammation $(n=9)$; vascular lesion $(n=6)$; nonbleeding polyp or mass $(n=2)$; and whipworms $(n=1)$ (Table 1).

Management of ulcerations: Seven cases of ulcerations were identified on CE, with the majority $(n=5)$ located in the duodenum. None of the lesions were believed to be associated with a progressive disorder such as Crohn disease, but two cases (28.6\%) were treated accordingly for NSAID use and Helicobacter pylori infection. Most of the ulceration cases were treated supportively with iron supplementation (Table 1).

Management of erosions/inflammation: Nine cases of erosion/inflammation were identified on CE. The causes of erosion and/or inflammation were definitively identified in only three subjects (33.3\%): Cameron erosions due to hiatus hernia; and erosions/inflammation due to Crohn disease and celiac disease. Hence, the etiologies were nonspecific for seven subjects in this group (77.8\%), who were treated supportively with iron supplementation or hemoglobin monitoring (Table 1).

Management of vascular lesions: Clinically significant vascular lesions were found in six cases, three of which $(50 \%)$ required interventions beyond supportive iron supplementation. One patient had nonbleeding angiodysplastic lesions in the gastric antrum requiring argon plasma coagulation. One of the three cases with duodenal lesions required intermittent, infrequent blood transfusion. The one case with jejunal lesions failed repeated endoscopic therapies and subsequently required laparotomy with intraoperative endoscopy and cautery. The remaining cases were supplemented with iron given the relatively mild degree of anemia (Table 1 ).

Management of nonbleeding polyps/mass: One of the two subjects in this group was diagnosed with Cowden syndrome - a multiple hamartoma syndrome characterized by tumour-like growths - and was managed supportively via iron supplementation. The other subject had a suspected jejunal polyp that was poorly visualized due to excessive debris. Doubleballoon enteroscopy was performed but only identified two aphthous ulcerations instead of the suspected lesion. Since then, this patient has remained well with iron supplementation (Table 1).

Management of whipworms: The one patient in this group was treated with mebendazole (Table 1). 


\section{Correlation}

Clinical factors in this group of patients were explored for correlations with positive findings on CE. The factors examined included: previous abdominal surgery, known gastric antral vascular ectasia, known Crohn disease, known celiac disease, known diverticulosis, change in bowel movement, hemorrhoids, selective serotonin reuptake inhibitor use, proton-pump inhibitor (PPI) use, NSAID use and steroid use. Only two factors demonstrated correlation: PPI use $(n=7)$ and NSAID use $(n=6)$. Of the PPI users with positive findings, erosion or inflammation was found in two, ulceration was found in three, polyps were found in one and vascular lesions were found in one. Of the six subjects who were on NSAIDs, erosion or inflammation was found in four and ulceration was found in two.

\section{Group B}

Findings: Group B consisted of 69 patients with negative/normal findings on CE (69 of 97 [71.1\%]). Ten of these 69 normal studies (14.5\%) were incomplete to the cecum, but the duration of the study was sufficient to visualize an extensive amount of the small bowel $(>2 \mathrm{~h})$.

The IDA in these patients with negative/normal findings was believed to be caused or exacerbated by the following: diet/low iron intake $(n=34)$; menorrhagia $(n=8)$; chronic renal failure $(n=3)$; malabsorption ( $n=8)$; use of NSAIDs $(n=2)$; missed colon cancer (found a few months later on colonoscopy) $(\mathrm{n}=1)$; single nonbleeding angiodysplastic lesions that could have bled intermittently $(n=3)$; low bone marrow function $(n=1)$; splenomegaly with sequestration $(n=1)$; hemolysis $(n=1)$; terminal ileal varices $(n=1)$; possible intermittent bleed from telangiectasias $(n=1)$; and possible bleeding from Cameron erosions in the hiatus hernia area previously identified on upper endoscopy but not on CE $(n=5)$.

Management: The majority of the subjects with normal CE were managed supportively with iron supplementation or hemoglobin monitoring. One (1.4\%) subject with terminal ileal varices on CE was subsequently diagnosed with autoimmune hepatitis and started on immunosuppressive therapy. Two subjects (2.9\%) underwent colonoscopy after CE. For the first patient, the previous colonoscopy was two years before $\mathrm{CE}$; therefore, the procedure was repeated for screening. The second patient's known cecal erythema was poorly visualized on $\mathrm{CE}$, which justified the need for a repeat colonoscopy. After the respective endoscopic investigations, both patients were managed supportively as required. Four subjects $(5.8 \%)$ underwent additional workup to exclude hemolysis post-CE.

Two $(2.9 \%)$ subjects underwent repeat CE study, which were normal after a CE with poor visualization of the small bowel (Figure 1).

\section{Group C}

Group C consisted of three subjects with incomplete CE studies (3.1\%). Two were recommended to undergo repeat CE. One patient was not referred for a repeat $\mathrm{CE}$ and was managed supportively.

\section{DISCUSSION}

Our positive yield in IDA patients who appeared to have no evidence of GI bleeding was $25.7 \%$ ( 25 of 97). However, after excluding those with normal findings, but whose IDA was at least partially attributed to extraintestinal causes, such as low dietary iron intake $(n=34)$ and menorrhagia $(n=8)$, the positive yield became $45.5 \%$ ( 25 of 55 ). Although this is equivalent to the overall yield of $45 \%$ for all of the CE studies conducted at our institution, the location of the lesions and the subsequent management strategies have significant resource utilization implications.

The consensus statement from the 2005 International Conference on Capsule Endoscopy (ICCE) recommends CE after initial negative esophagogastroduodenoscopy and colonoscopy (12). In a previous study conducted at our institution, a significant proportion $(27 \%)$ of culprit lesions were found by repeating standard endoscopy before performing CE (13). Peter et al (14) found that $9 \%$ of patients had lesions in the upper GI tract that had been overlooked on standard

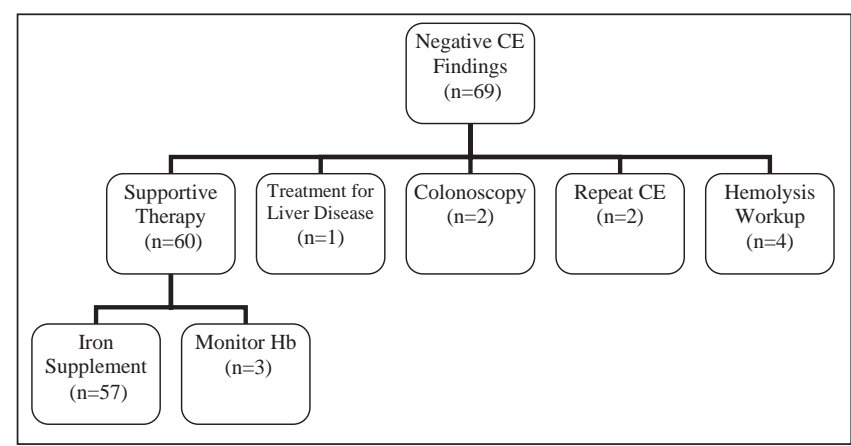

Figure 1) Management of negative/normal findings on capsule endoscopy (CE). Hb Hemoglobin

endoscopy, and that the treatment changed in $82 \%$ of these patients after lesions were found on CE. Both studies found a need for a second endoscopy in the diagnostic algorithm.

In the present study, the majority of the positive findings were believed to be within reach of a standard endoscope ( $n=19$ [76\%]), and only six of 25 patients (24\%) received any treatment beyond supportive management. While some patients required medical intervention, these conditions (eg, celiac disease, antral vascular lesions, peptic ulcer disease and whipworms) could have all been managed without the use of CE $(12,13,15-17)$.

In essence, only two patients (4\%) required specific small intestinal therapy (laparotomy for bleeding proximal small bowel vascular lesions and Crohn disease therapy for terminal ileal erosions) as a result of CE finding in the entire cohort. Thorough history taking and well performed standard endoscopies, with or without repetition, before CE may identify IDA patients least likely to benefit from CE and improve resource utilization.

To answer our second objective, no significant comorbidity was found to be consistent among the group with positive findings. However, of the 25 positive studies, the most common factor was the use of PPI ( $n=7[28.0 \%])$, likely initiated to decrease the possibility of upper GI bleeding. The second most common factor was the use of NSAIDs ( $n=6$ [24.0\%]). NSAIDs have erosive effects on the intestinal mucosa, which can denude both gastric and small intestinal tissue (18). This can, therefore, produce a positive finding on CE despite the lack of true pathology.

Most patients (both positive and negative findings) were managed supportively $(n=79)$, with oral or parenteral iron supplementation being the most common therapy $(n=72)$.

Interestingly, $72 \%$ of the group A patients were recommended supportive therapy $(n=18)$. This was the largest group in terms of management strategies for positive $\mathrm{CE}$ yields. As for negative findings (group B patients), $87.0 \%(n=60)$ resulted in supportive management, while the remaining management groups consisted of only a few patients each. The results in group B were expected because these patients did not demonstrate any significant GI abnormalities on CE; therefore, no other intervention was taken and they were supportively treated for IDA. Collectively, these two groups received similar management strategies regardless of findings. For some patients, this may suggest that it is irrelevant whether they have a positive or negative finding on $\mathrm{CE}$ because they would ultimately incur the same treatment.

In agreement with the ICCE consensus statement from 2005 (12), we found that sufficient selection criteria for CE has not yet been established for IDA patients.

\section{Limitations}

Limitations of the present study include: single-centre experience; single endoscopist reader; and the inability of FOBT negativity to exclude intermittent occult blood loss, for which there is no gold standard for detection. 


\section{CONCLUSION}

The overall yield of CE in the setting of IDA without evidence of GI bleeding has a very low diagnostic yield (25\%). It remains 'low yield' despite achieving a positivity rate of $45 \%$, which is similar to our overall CE experience, after excluding those whose IDA may be attributed to low dietary intake and menorrhagia. The main issue revolves around the fact that most of the lesions found on CE were, in fact, within reach of a standard endoscope, meaning they could have been managed without using CE. Additionally, post-CE management remained mostly supportive in the form of iron supplementation regardless of findings, further highlighting the need for adequate iron replacement before initiating CE studies. Thus, for IDA patients referred to this particular centre with no evidence of GI bleeding, the value of $\mathrm{CE}$ is extremely limited. These data can be used to decide on the appropriate use of this important small bowel diagnostic tool and also to advise patients accordingly so that both the physician and the patient have realistic expectations if the CE study is performed.

\section{REFERENCES}

1. Iddan G, Meron G, Glukhovsky A, Swain P. Wireless capsule endoscopy. Nature 2000;405:17.

2. Swain P, Adler D, Enns R. Capsule endoscopy in obscure intestinal bleeding. Endoscopy 2005;37:655-9.

3. Fireman Z, Kopelman Y. The role of video capsule endoscopy in the evaluation of iron deficiency anemia. Dig Liver Dis 2004;36:97-102.

4. Leighton JA, Triester SL Sharma VK. Capsule endoscopy: A metaanalysis for use with obscure gastrointestinal bleeding and Crohn's disease. Gastrointest Endosc Clin N Am 2006;16:229-250.

5. Albert JG, Nachtigall F, Wiedbrauck F, et al. Minimizing procedural cost in diagnosing small bowel bleeding: Comparison of a strategy based on initial capsule endoscopy versus initial double-balloon enteroscopy. Eur J Gastroenterol Hepatol 2010;22:679-88.
6. Van Gossum A, Ibrahim M. Video Capsule endoscopy: What is the future? Gastroenterol Clin N Am 39 2010;807-26.

7. Toy E, Rojany M, Sheikh R, Mann S, Prindiville T. Capsule endoscopy's impact on clinical management and outcomes: A single-center experience with 145 patients.

Am J Gastroenterol 2008;103:3022-8.

8. Riccioni ME, Urgesi R, Spada C, et al. Unexplained iron deficiency anaemia: Is it worthwhile to perform capsule endoscopy? Dig Liver Dis 2010;42:560-6.

9. Fernández-Bañares F, Monzón H, Forné M. A short review of malabsorption and anemia. World J Gastroenterol 2009;15:4644-52.

10. Schulzke JD, Tröger H, Amasheh M. Disorders of intestinal secretion and absorbtion. Best Pract Res Clin Gastroenterol 2009;23:395-406.

11. Monroe JA, Godwin JH, Godwvin TA. HIV/AIDS case histories: Iron deficiencv anemia and altered iron metabolism in HIV infection. AIDS Patient Care STDS 2000;12:667-9.

12. Pennazio M, Eisen G, Goldfarb N. ICCE consensus for obscure gastrointestinal bleeding. Endoscopy 2005;37:1046-50.

13. Hadisfar O, Enns R. Retrospective study of missed small bowel lesions. Can J Gastroenterol 2010;24(Suppl A)A:1-200:A170 (Abstr). <www.pulsus.com/cddw2010/abs/170.htm>.

14. Peter S, Heuss LT, Beglinger C, Degen L. Capsule endoscopy of the upper gastrointestinal tract - the need for a second endoscopy. Digestion 2005;72:242-7.

15. Catassi C, Fasano A. Celiac disease diagnosis: Simple rules are better than complicated algorithms. Am J Med 2010;123:691-3.

16. Stenström B, Mendis A, Marshall B. Helicobacter pylori - the latest in diagnosis and treatment. Aust Fam Physician 2008;37:608-12.

17. Ok KS, Kim Y-S, Song J-H, et al. Trichuris trichiura infection diagnosed by colonoscopy: Case reports and review of literature. Korean J Parasitol 2009;47:275-80.

18. Caunedo-Alvarez A, Gómez-Rodríguez BJ, Romero-Vázquez J, et al. Macroscopic small bowel mucosal injury caused by chronic nonsteroidal anti-inflammatory drugs (NSAID) use as assessed by capsule endoscopy. Rev Esp Enferm Dig 2010;102:80-5. 


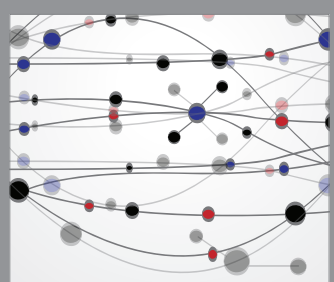

The Scientific World Journal
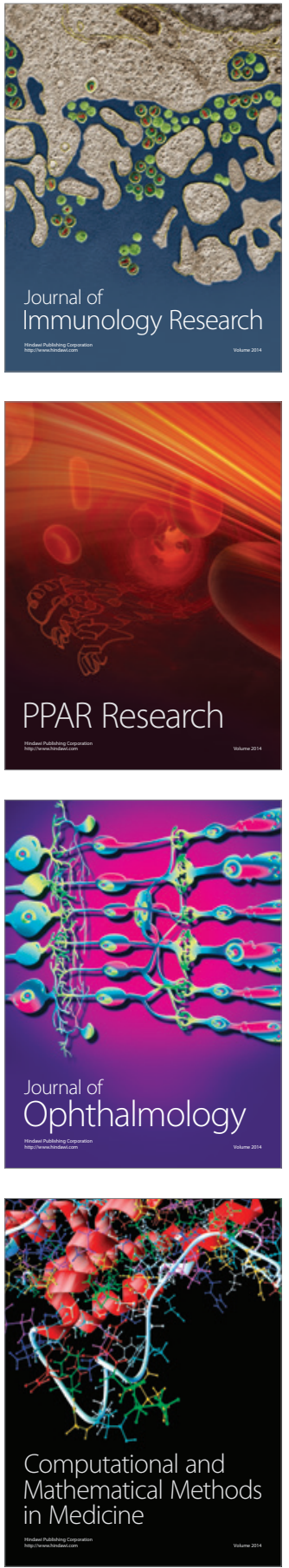

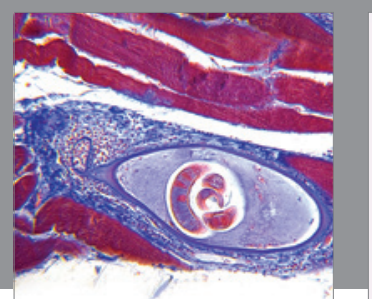

Gastroenterology Research and Practice

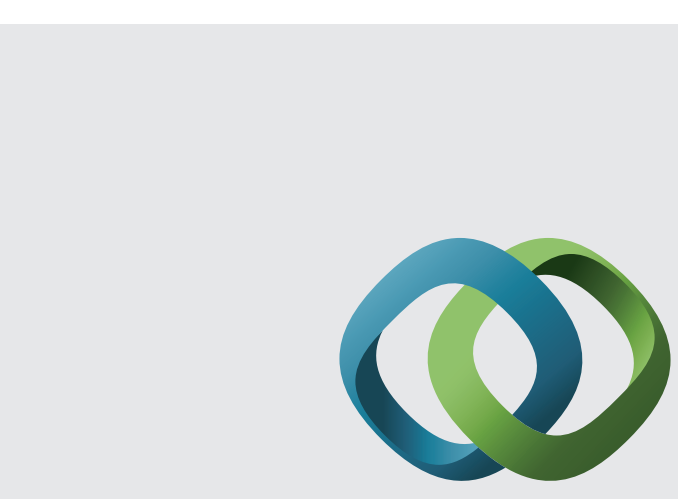

\section{Hindawi}

Submit your manuscripts at

http://www.hindawi.com
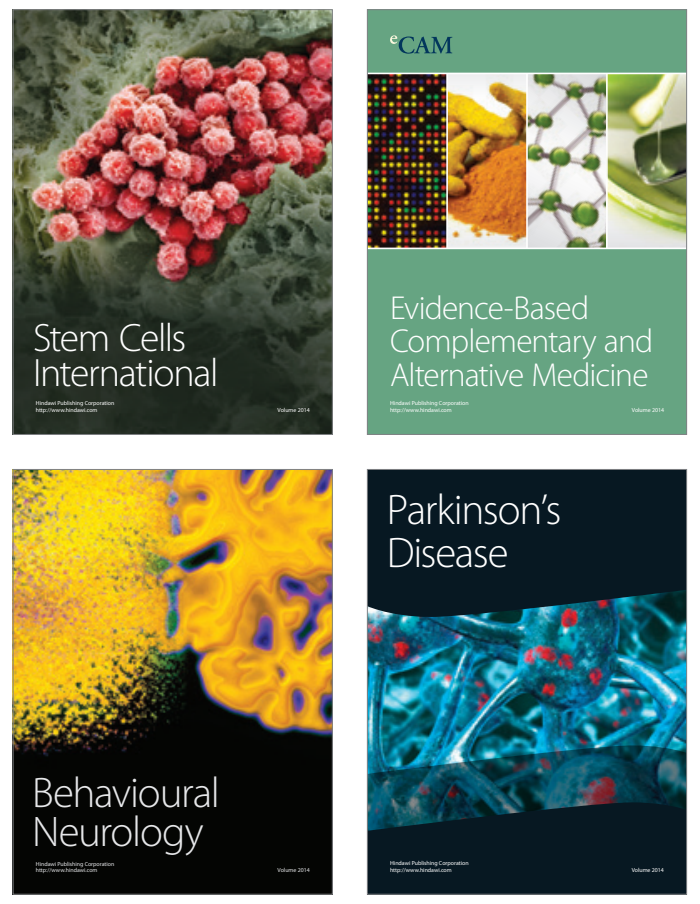
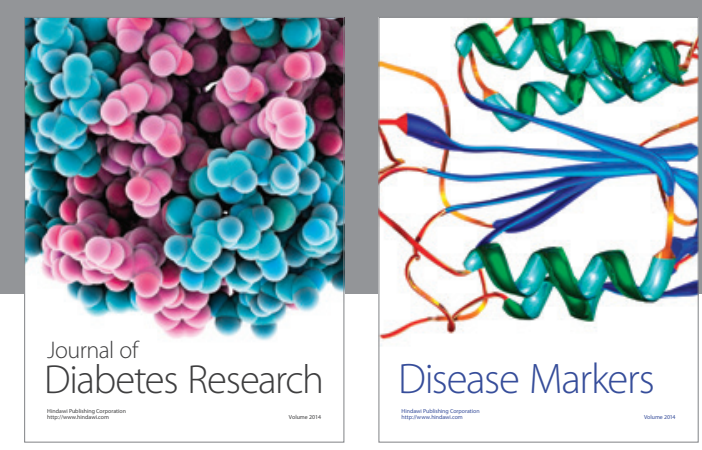

Disease Markers
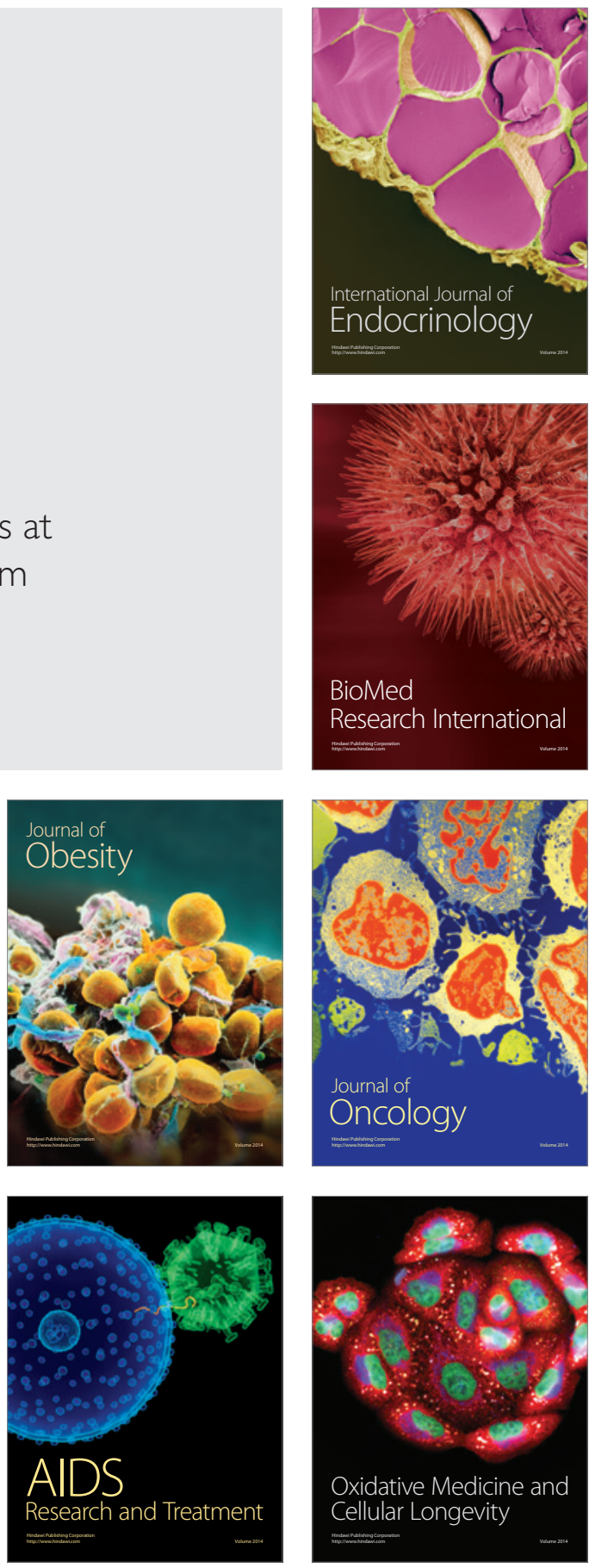